\title{
La transparencia institucional y mediática del coronavirus. Un análisis de los portales de datos y de los medios de comunicación digitales en Iberoamérica
}

\section{The institutional and media transparency of the coronavirus. An analysis of data portals and digital media in Ibero-America}

María Díez-Garrido. Universidad de Valladolid. España

maria.diez.garrido@uva.es

$[\mathrm{CV}]$ (1) $\mathrm{G}$

Cristina Renedo Farpón. Universidad de Valladolid, España

Renedof.cristina@gmail.com

$[\mathrm{CV}]$ ( ) $\mathrm{G}$

Este artículo se enmarca dentro del proyecto "Estrategias, agendas y discursos en las cibercampañas electorales: medios de comunicación y ciudadanos" (referencia: CSO2016- 77331-C2-1-R), del grupo Mediaflows, financiado por el Ministerio de Economía y Competitividad del Gobierno de España.

Cómo citar este artículo / Referencia normalizada

Díez-Garrido, M. y Renedo Farpón, C. (2020). La transparencia institucional y mediática del coronavirus. Un análisis de los portales de datos y de los medios de comunicación digitales en Iberoamérica. Revista Latina de Comunicación Social, 78, 393-418. https://www.doi.org/10.4185/RLCS-2020-1482

\section{RESUMEN}

Introducción. La emergencia sanitaria producida por el virus COVID-19 ha tenido diversas consecuencias en el panorama institucional y en el mediático. Ante una situación de esta magnitud, las instituciones gubernamentales han tenido que introducir medidas de transparencia en sus rutinas diarias para ofrecer a la ciudadanía una información actualizada y de calidad sobre la pandemia. Esto ha afectado también a las prácticas periodísticas, ya que el volumen de información dedicada al coronavirus ha ido en aumento en los medios de comunicación. El periodismo de datos se presenta como una de las fórmulas más recurrentes de los medios de comunicación digitales, con el desarrollo de mapas y gráficos que utilizan los datos oficiales. Metodología. Este trabajo de investigación pretende conocer, por un lado, el grado de transparencia informativa de los gobiernos de Iberoamérica sobre la enfermedad, así como el desarrollo del periodismo abierto, el periodismo de datos y otras prácticas por parte de los medios de comunicación para informar sobre el coronavirus. Para ello, se ha elaborado una evaluación de los portales de información sobre el COVID-19 de 12 
países iberoamericanos y de los dos medios digitales más relevantes de cada país. Conclusiones. A pesar del enorme esfuerzo realizado por las instituciones para informar a la ciudadanía de la emergencia sanitaria, los portales de transparencia presentan diversas deficiencias. Los medios de comunicación, por su parte, han desarrollado principalmente el periodismo de datos, pero no han fomentado la transparencia mediática ni la participación de la ciudadanía en la elaboración de contenidos.

PALABRAS CLAVE: periodismo abierto; coronavirus; transparencia; datos abiertos; participación; colaboración; portales.

\begin{abstract}
Introduction. The health emergency caused by the COVID-19 virus has had various consequences on the institutional and media scene. Faced with a situation of this magnitude, governments have introduced transparency measures into their daily routines to provide citizens with up-to-date, quality information on the pandemic. This has also affected journalistic practices, as the volume of information dedicated to the coronavirus has been increasing in the media. Data journalism is presented as one of the most recurrent formulas of digital media, with the development of maps and graphs using official data. Methodology. This research aims to find out, on the one hand, the degree of information transparency of Ibero-American governments on the disease, as well as the development of open journalism, data journalism and other practices by the media to report on the coronavirus. To this end, an evaluation has been made of the COVID-19 information portals in 12 Ibero-American countries and of the two most relevant digital media in each country. Conclusions. Despite the enormous effort made by the institutions to inform the public about the health emergency, the transparency portals present various deficiencies. The media, on the other hand, have mainly developed data journalism, but they have not promoted media transparency or citizen participation in the elaboration of contents.
\end{abstract}

KEYWORDS: open journalism; coronavirus; transparency; open data; participation; collaboration; portals.

\title{
CONTENIDO
}

1. Introducción. 2. Marco teórico. 2.1. La necesidad de una transparencia sanitaria. 2.2. Nuevas tendencias mediáticas: periodismo abierto y transparente. 3. Objetivos, hipótesis y preguntas de investigación 4. Metodología. 4.1. Transparencia institucional sobre el coronavirus. 4.2. Medios de comunicación: periodismo de datos, fact-checking, transparencia y participación mediática. 5. Resultados. 5.1. Páginas institucionales de los gobiernos. 5.2. Medios de comunicación. 6. Conclusiones. 7. Bibliografía. 8. Autoras. 9. Anexos.

\section{Introducción}

El estudio de la transparencia informativa en los últimos años ha destacado múltiples beneficios de la publicación de información del sector público. Destaca el desarrollo de la eficiencia y la innovación en los servicios ofrecidos a la ciudadanía por las instituciones que publicitan la información (Ruijer et al., 2019), así como la oportunidad de evaluar y controlar al poder por parte de la ciudadanía, que puede examinar los datos públicos y exigir responsabilidades a las administraciones (Caridad Sebastián y Martínez Cardama, 2016).

En este artículo, la sanidad se entiende como un servicio público. Por ello, la publicación de datos relacionados con la sanidad puede derivar en una mayor eficacia del servicio y en el desarrollo de 
investigaciones que utilicen dichos datos para examinarlos o como fuente de información. A esto se suma la monitorización por parte de la ciudadanía y de los medios de comunicación que pueden ejercerse con los datos sanitarios.

La crisis del coronavirus ha implicado numerosos debates relacionadas con la publicación de datos por parte de las instituciones pertinentes, así como acerca de su tratamiento en los medios de comunicación y la demanda de una mayor transparencia ha ido unida al avance de la pandemia. En este sentido, desde los propios medios, hubo diversas reflexiones (Barón, 2020; Maldita, 2020; Escudero, 2020), sobre la necesidad de reforzar la transparencia, publicar los datos en formatos accesibles y unificar criterios entre instituciones para que los datos pudieran ser comparables en los contenidos realizados por los periodistas y para que la población recibiera información de calidad.

A este contexto hay que añadir un clima de desinformación constante en las redes sociales, del que la propia Policía Nacional de España se hizo eco (EFE, 2020), e incluso la Organización Mundial de la Salud (2020) habló del peligro de la infodemia, la corriente de noticias falsas que ha acompañado a la pandemia. En este sentido, surge la necesidad de reforzar disciplinas como el fact-ckecking (Amazeen, 2017), que utilizan datos oficiales para contrastar la información y combatir los bulos que se viralizan en WhatsApp, Twitter, Facebook y otros medios sociales, así como de reforzar la confianza en los medios de comunicación y de acercarlos a la ciudadanía.

Esta investigación pretende estudiar el grado de desarrollo de la transparencia institucional respecto a la crisis del coronavirus en países iberoamericanos. Se quiere conocer el tipo de datos publicados por los gobiernos y autoridades sanitarias en sus portales de transparencia, sus características y las posibilidades que ofrecen. Además, también se pretende investigar el desarrollo del periodismo abierto, el periodismo de datos y el fact-checking en los medios de comunicación de estos países para informar sobre la pandemia del coronavirus.

\section{Marco teórico}

\subsection{La necesidad de una transparencia sanitaria}

Los países democráticos han vivido un auge por aumentar la transparencia de las políticas en los países democráticos, que ha implicado la aprobación de normativas y estas han ido de la mano de los avances tecnológicos (Palomares Herrera, 2017). Se entiende la transparencia como la publicación cuyo objetivo es mantener informada a la ciudadanía y rendirle cuentas. Esta puede darse de forma activa, a través de la publicación voluntaria de información en Internet, y de forma pasiva, mediante peticiones de acceso a la información (Manfredi, 2017, Paniagua et al., 2017).

Este desarrollo de la apertura informativa no es ajeno al campo de la salud. Esto se debe a las consecuencias que tiene el régimen sanitario de un territorio en el bienestar de la población, de forma que la información se vuelve un bien que la ciudadanía busca y necesita, pues le afecta de forma directa en lo referido al bienestar público y personal. Esto se hizo evidente en la pandemia ocasionada por el coronavirus, pues implicó un cambio drástico en la vida de la ciudadanía.

Las motivaciones que llevan a las administraciones a desarrollar la transparencia son diversas. Así, los procesos de apertura informativa buscan la recuperación de la legitimidad ciudadana, la prevención de la corrupción y la promoción de la participación (Kemp, 2020), entre otras razones. Uno de los aspectos más destacados de la transparencia es que esta deriva una mayor efectividad y eficiencia de los servicios ofrecidos por la administración (Huijboom y Broek, 2011). Al darse a 
conocer datos sobre el funcionamiento de las administraciones y sus estructuras, esto facilita la toma de decisiones y permite que las medidas sean fruto de la información.

Las políticas de transparencia y rendición de cuentas en los sistemas sanitarios pueden conducir a una mejora de sus resultados sanitarios, pues, al hacer accesibles los datos, genera conocimiento, y los profesionales pueden adelantarse a los nuevos retos, lo cual aumenta su eficiencia y mejora la planificación (García-Altés y Barba, 2013).

Ford et al. (2019) destacan los grandes avances en investigaciones sanitarias que son consecuencia de la creciente disponibilidad de datos, así como del desarrollo de herramientas computacionales para procesar estos datos. La transparencia sanitaria y la evolución tecnológica suponen una importante contribución al conocimiento y, por tanto, a la investigación -especialmente en Ciencias de la Salud.

Las políticas de transparencia estimulan la innovación y el crecimiento económico, que son requisitos indispensables para contar con unos servicios públicos más efectivos (Ruijer et al., 2019). La sanidad, en este artículo, se entiende como un servicio público indispensable para el desarrollo del estado del bienestar.

Paradójicamente, la transparencia puede servir para maquillar la opacidad, como destacan Ruijer et al (2019), a través de la publicación de información en bases de datos incomprensibles o difundiendo datos que son seguros, es decir, que no contienen informaciones que puedan perjudicar a la institución que lo divulga. Por ello, la información debe ser comprensible.

Una de las principales exigencias en cuanto a la transparencia es la referente a su reutilización. A esto hacen referencia las normativas, como la Ley de Transparencia, Acceso a la Información Pública y Buen Gobierno de España hace en su artículo 5: "Se establecerán los mecanismos adecuados para facilitar la accesibilidad, la interoperabilidad, la calidad y la reutilización de la información publicada así como su identificación y localización” (Ley 19/2013).

Estas exigencias se refieren a la oportunidad de la ciudadanía, así como de compañías empresariales, de generar servicios de información a partir del aprovechamiento de la información del sector público (Cerrillo-i-Martínez, 2012). Y es que la información tiene un gran valor económico y social que puede ser explotado de muy diversas formas, como aplicaciones móviles, cartografías y diferentes servicios de información basados en el análisis de conjuntos de datos.

Es preciso, por tanto, que las instituciones compartan la información en formatos adecuados para su reutilización y que sean accesibles. Ello permite la monitorización del sector público, que a su vez incrementa la inteligencia colectiva (Caridad Sebastián y Martínez Cardama, 2016).

El acceso de los ciudadanos a conjuntos de datos les da la oportunidad de evaluar lo que las administraciones públicas, en quienes han depositado la responsabilidad y confianza, deciden. Se tienen que dar ciertas características en estos portales de datos y Lourenço (2015), en este sentido, destaca que la información debe ser de calidad, precisa, completa, visible, comprensible, actualizada, detallada y útil.

Iberoamérica representa una región interesante en el acceso a la información. En este sentido, La Carta Iberoamericana de Calidad en la Gestión Pública indica que las administraciones deben «ser transparentes en su gestión, abiertas al escrutinio público, tolerantes a la crítica y permeables a las propuestas de mejora y de cambio provenientes de la ciudadanía» (CLAD, 2008:8). 
Según Cotino Hueso (2017), es una de las regiones más avanzadas en transparencia, más que Europa. El autor destacó el reconocimiento del acceso a la información como derecho humano por la Corte Interamericana de Derechos Humanos, así como la presencia de los países iberoamericanos en la Alianza para el Gobierno Abierto.

Ruiz-Rico Ruiz (2019) destaca que la Ley 9 de mayo 2016 de transparencia y acceso a la información pública de México es más exhaustiva que la norma española en la obligación de las instituciones de buscar información que debe estar bajo su poder. Mientras que la normativa española tiende a excluir la información que no esté en poder del sujeto obligado, la mexicana exige que se realice una búsqueda exhaustiva si esta información es su competencia.

Resulta también interesante el artículo 23 de la Ley orgánica de transparencia y acceso a la información pública de Ecuador, que señala las sanciones a funcionarios y empleados públicos y privados que denieguen de forma ilegítima el acceso a la información.

Sin embargo, Cotino Hueso (2017) subraya que la transparencia jurídica y normativa en Iberoamérica dista mucho de la realidad, lo cual no conduce a la rendición de cuentas y a la lucha contra la corrupción. Esto muestra la necesidad de aprobar leyes de acceso a la información al tiempo que se formulen recursos y procesos para garantizar que la transparencia se lleva a cabo en la práctica.

\subsection{Nuevas tendencias mediáticas: periodismo abierto y transparente}

La transparencia tiene como consecuencia el acceso de la ciudadanía a bases de datos, que a su vez deriva en la reutilización de estas informaciones para diferentes cuestiones. Surgen así nuevas oportunidades de negocio basadas en el uso del modelo Open Data (Paucar Carrión y Coronel-Salas, 2019), sea cual sea su procedencia (pública o privada):

El usuario con esta vertiente no sólo propicia información con acceso libre a los contenidos,

sino también pone a disposición sin restricción técnica ni legal los datos; permitiendo generar

y/o curar contenidos. Así la comunidad puede consultar, verificar contrastar y si requiere,

reutilizar y redistribuir la información sin condiciones en: licencia, formato y acceso libre.

(Paucar Carrión y Coronel-Salas, 2019: 488)

El periodismo puede verse beneficiado en este sentido por la transparencia, con disciplinas que aprovechen los datos publicados para realizar nuevos contenidos. Una de estas prácticas es el periodismo de datos, que utiliza las miles de fuentes informativas accesibles en Internet para crear piezas periodísticas basadas en narrativas actuales y la visualización de datos (López-García et al, 2016). Se trata de una práctica periodística que utiliza como fuente grandes bases de datos para narrar historias a través de infografías, mapas interactivos y otras herramientas disponibles en Internet (Gray et al., 2012). El perfil del periodista de datos, según los mismos autores, requiere conocimientos sobre gestión de bases de datos, que se suma a competencias con la informática, estadística, rastreo y análisis cuantitativos y visualización de la información.

En este contexto es importante señalar también la proliferación de la figura del prosumidor (Tofler, 1980), que ha modificado los antiguos roles entre emisor y receptor, permitiendo que el último pueda 
asumir la características de construcción y difusión de información que hasta entonces solo eran propias de los medios de comunicación. Los usuarios, con un papel cada vez más activo en la construcción del discurso periodístico, pueden ejercer un nuevo doble papel, fiscalizador y colaborador de los medios, y esto ha propiciado la necesidad de avanzar hacia un periodismo más transparente que fomente la capacidad de los medios con tres objetivos: descubrir su forma de trabajar, formular contenidos reutilizables y aprovechar el capital social del prosumidor para colaborar en el proceso informativo (Campos-Domínguez y Redondo, 2015).

Con estas características, avanzamos hacia un concepto de Periodismo de código libre (Sampedro, 2015) en el que los usuarios pueden acceder a la totalidad de los contenidos en bruto y colaborar para mejorar las historias, añadiendo nuevos datos o colaborando en la mejora del tratamiento de la información ya obtenida. De esta forma se eleva al periodismo para pensar en la información como un proceso en continua evolución y no como un producto terminado (Lewis y Usher, 2013).

Respecto al aprovechamiento del capital social del prosumidor, en un principio los medios de comunicación se interesaron por introducir elementos sencillos y limitados de participación, como el uso de redes sociales, comentarios, valoración de noticias o envío de contenidos sencillos como fotografías. Estas prácticas son utilizadas más como nuevas formas de distribución y fidelización de la audiencia y limitan su participación a una interacción más superficial y localizada que a contribuir verdaderamente al contenido del medio (Bachmann, 2012). Estudios más recientes (Barredo y Díaz, 2017) refuerzan esta idea de la limitación de la participación social de los usuarios, restringiendo suy creatividad e involucración por asociar las rutinas profesionales a soportes convencionales, aunque sí reconocen que la interacción es actualmente clave para los medios como un proceso persuasivo.

Especialmente en contextos como el provocado por el COVID-19 en los que se producen una gran cantidad de datos a nivel mundial, es interesante valorar el potencial de participación ciudadana en la recolección y tratamiento de ese tipo de información, especialmente en el contexto de las multitudes inteligentes, que pueden aplicar el crowd-sourcing (Anderson et al, 2013) para ampliar, completar o mejorar los productos periodísticos.

Con referencia a la potencialidad de los medios para generar contenido reutilizable, así como mostrar su forma de trabajar, hay que pensar en formas de transparencia que van más allá de los sistemas de rendición de cuentas tradicionales de los medios de comunicación, por ello es conveniente ahondar en nuevos mecanismos surgidos en el marco de Internet y la web 2.0 (Vegas, De los Ríos y Anguiano, 2016). Estos nuevos mecanismos, de redacciones abiertas, publicación de metodología de trabajo o liberación de fuentes, siguen la línea de ese periodismo de código abierto, que basa sus principios en los del código open source.

La transparencia, tanto en las fuentes como en los procesos de construcción de información periodística, es además un elemento que fortalecería la competencia mediática como recurso contra la desinformación, un fenómeno que se ha propagado de forma exponencial a través de los medios sociales, internet, la telefonía móvil y el uso de inteligencia artificial (Vivar, 2019) y que es especialmente incipiente en contextos de información política y de gran interés público.

Diferentes portales especializados en fact checking o verificación de contenidos ya aplican la transparencia dentro de su método de trabajo (Lotero-Echeverri et al, 2018), para mostrar a los usuarios cómo se construye el contenido y que estos adquieran la competencia suficiente para detectar si una información es falsa o está manipulada. Por eso es relevante abordar también el fomento de esta transparencia en los medios de comunicación más generalistas y no especializados en la verificación de contenidos, ya que son igualmente los medios más consumidos. 


\section{Objetivos, hipótesis y preguntas de investigación}

Este trabajo de investigación tiene dos objetivos fundamentales. El primer objetivo que se pretende alcanzar es explorar el grado de apertura informativa de los gobiernos iberoamericanos respecto al nuevo coronavirus durante los primeros meses de la pandemia, es decir, estudiar la transparencia institucional con respecto a la enfermedad y al nivel de afectación en estos países.

El segundo objetivo principal es comprobar el grado de apertura de los medios de comunicación digitales en dichos países y examinar el desarrollo de prácticas periodísticas con la finalidad de hacer comprender a la población la situación de emergencia mundial durante los primeros meses de epidemia.

Los siguientes objetivos específicos se tuvieron en cuenta durante la realización de esta investigación:

1. Realizar una comparación entre los diferentes países.

2. Comprobar si aquellos países más afectados fueron los que más desarrollaron su transparencia y en los que más desarrollo periodístico hubo.

3. Estudiar los datos abiertos publicados por los gobiernos.

4. Examinar si las instituciones sanitarias tratan de publicar datos reutilizables.

5. Analizar el fomento de la transparencia y la participación por parte de los medios digitales seleccionados.

Las hipótesis fueron las siguientes:

H1. Los gobiernos presentan deficiencias en su transparencia sobre el coronavirus.

H2. Los medios de comunicación no han desarrollado el periodismo abierto durante la crisis del coronavirus para informar sobre la pandemia y hay escasos ejemplos de ello.

H3. Los medios de comunicación han practicado el periodismo de datos para informar sobre el coronavirus.

También se plantearon estas preguntas de investigación, con el fin de cumplir los objetivos del trabajo:

1. ¿Hay diferencias entre los países europeos y los americanos?

2. ¿Los países con más personas infectadas han presentado diferencias respecto al resto?

3. ¿Qué tipo de datos comparten los gobiernos para informar sobre el coronavirus?

4. ¿Se fomenta de alguna forma la participación y la reutilización de los datos?

5. ¿Promueven los medios digitales la transparencia y la participación de alguna forma?

\section{Selección de la muestra y metodología}

Con la finalidad de analizar tanto los portales de información sobre coronavirus creados por los Gobiernos, como la cobertura realizada por los medios de comunicación, el interés se centró en los países iberoamericanos. Se pretendía realizar una comparación internacional que aglutinara dos continentes diferentes y, por ello, se escogió una muestra de doce países de Iberoamérica, entre los que se incluyeron España y Portugal. Los países elegidos finalmente fueron los doce que en el momento en el que se diseñó la investigación (25/03/2020) tenían más personas infectadas por coronavirus y fueron los siguientes: España, Brasil, Portugal, Chile, Ecuador, Panamá, México, Perú, Argentina, Colombia, Uruguay y Costa Rica. 
Respecto a los medios de comunicación digitales, se seleccionaron los dos más visitados en cada país ${ }^{1}$. Así, la muestra de portales institucionales y de medios digitales fue la siguiente:

Tabla 1. Selección de la muestra para la investigación

\begin{tabular}{|l|l|l|}
\hline País & Medios de comunicación \\
\hline España & La Vanguardia & El País (España) \\
\hline Brasil & O Globo & O Estado de Sao Paulo \\
\hline Portugal & Público & Jornal de Noticias \\
\hline Chile & Biobio & Emol \\
\hline Ecuador & La República (Ecuador) & Vistazo \\
\hline Panamá & La Estrella & Prensa \\
\hline México & Aristegui Noticias & El Universal Online \\
\hline Perú & El Comercio & La República (Perú) \\
\hline Argentina & Clarín & Infobae \\
\hline Colombia & El Tiempo & Publímetro \\
\hline Uruguay & El País (Uruguay) & República \\
\hline Costa Rica & La Nación & Telética \\
\hline
\end{tabular}

Fuente: elaboración propia a partir de índices de audiencias online

Respecto a la fecha en la que se codificó este trabajo, cabe destacar que en un principio, se eligió el mes de abril. Sin embargo, tras observar que en las páginas web se produjeron algunas transformaciones, se decidió finalmente repetir la codificación en el mes de mayo, momento en el que la pandemia mundial ya estaba muy avanzada, para codificar el material de nuevo. De este modo, se contó con resultados actualizados y con una mayor fiabilidad en los datos obtenidos.

El estudio contó con dos partes diferenciadas. La primera consistió en un estudio de los portales de transparencia creados por los gobiernos para informar acerca del COVID-19. La segunda parte fue un análisis de los medios de comunicación, en el que se quiso comprobar la apertura, transparencia y participación de dichos medios de comunicación, así como el desarrollo de ciertas prácticas periodísticas. Cabe destacar que en ambos estudios se realizó un pretest por parte de las codificadoras para comprobar que la medición era adecuada. A continuación, se explicarán los métodos seleccionados para ambas partes.

\subsection{Transparencia institucional sobre el coronavirus}

En primer lugar, se realizó un análisis de contenido de los portales de transparencia elaborados por los gobiernos para informar sobre el coronavirus a la ciudadanía. El objetivo era comprobar el grado de desarrollo de los portales abiertos y así estudiar la utilidad de estos para informar a la población,

\footnotetext{
${ }^{1}$ Salvo en el caso de Brasil, pues el primero (Folha de Sao Paulo) es de pago y no se podía acceder a su contenido sin tener un código postal brasileño.
} 
realizar contenidos periodísticos, así como para ser reutilizados por la ciudadanía para diferentes prácticas -por ejemplo, para la creación de aplicaciones-.

Por ello, se comprobó que, para comenzar, las instituciones gubernamentales contasen con un apartado específico en sus respectivos ministerios de Sanidad dedicados a informar sobre el COVID19. También se quiso saber si publicaban recomendaciones de prevención para la población general, información sobre la patología y recomendaciones para personas infectadas. Asimismo, acerca de las medidas tomadas por el Gobierno y cuestiones que afectan a la población, se estudió si los gobiernos compartían información sobre el material comprado (como mascarillas, guantes y otros elementos), las medidas tomadas por cada institución para hacer frente a la pandemia, datos sobre trabajadores afectados y medidas tomadas al respecto y contratos realizados relacionados con el coronavirus. Además, también resultó de interés saber si las administraciones publicaban preguntas frecuentes realizadas por la población, dada su utilidad en un caso como este.

Para evaluar la apertura informativa de estos portales de transparencia, fue importante analizar los datos abiertos. Así, en primer lugar, se estudió si los espacios web institucionales sobre el coronavirus tenían un repositorio de datos $\mathrm{y}$, en caso de existir, si en este se cumplían una serie de circunstancias, a saber:

- Se podían descargar los datos con un formato reutilizable.

- Estos datos eran actualizados al menos dos veces al día.

- Se aportaban al menos los siguientes datos:

- Datos por edad.

- Datos de ingresados.

- Datos de fallecimientos.

- Datos de altas hospitalarias.

- Datos de personas recuperadas.

- Datos por regiones.

- Pruebas realizadas.

- Pruebas positivas y negativas.

- Otros datos que pudieran resultar de interés para la investigación.

Otro aspecto relevante es que la información sea comprensible y, para ello, son muy útiles las visualizaciones de los datos. Por este motivo, se analizó si contaba con alguna visualización de la información y, en concreto, se quiso saber si esta fue en formato de mapa de infección, curva de infección o de otra forma.

\subsection{Medios de comunicación: periodismo de datos, fact-checking, transparencia y participación mediática}

Tras la realización del análisis de los portales institucionales, se pasó a la segunda parte de esta investigación, que se trató de un estudio de la apertura, la transparencia, la participación y el desarrollo de diferentes aspectos periodísticos en los medios de comunicación seleccionados en sus espacios dedicados al coronavirus. Así, en primer lugar se quiso saber si los medios contaban con una sección específica sobre el coronavirus en la portada, para agrupar las noticias sobre el tema de estudio.

Como se ha mencionado, se estudió el desarrollo de diversas prácticas periodísticas, como el periodismo de datos -en este sentido, se examinó si los medios contaban con mapas interactivos de infección, curvas de infección u otros gráficos-, el fact checking, alguna sección de actualización en tiempo real u otras prácticas periodísticas que se deban destacar. 
Respecto al desarrollo del periodismo abierto en los medios de comunicación, el análisis contó con dos partes: una dedicada a la transparencia y otra, a la participación y la colaboración. En el apartado dedicado a la transparencia, se estudió si los medios publicaban las bases de datos sobre el coronavirus, la metodología utilizada y las fuentes de una forma accesible. En el apartado de participación y colaboración se analizó si los medios pusieron a disposición del público canales de participación específicos sobre el COVID-19, si existían vías de colaboración en la elaboración de contenidos, y si existía una cooperación con otros medios de comunicación o diferentes entidades (asociaciones, instituciones). Por último, se añadió una sección al final de cada ficha de análisis para introducir cualquier aspecto de los medios de comunicación que pudiera ser relevante para el trabajo.

\section{Resultados}

\subsection{Páginas institucionales de los gobiernos}

Ante la situación de emergencia global ocasionada por el coronavirus, los gobiernos estatales se encargaron de nutrir sus portales digitales de información sobre la enfermedad, no solo de cara a los medios de comunicación, sino para la ciudadanía en general.

Como se ha mencionado en el apartado metodológico, la codificación se repitió porque detectamos que, a medida que avanzaba la pandemia, los gobiernos comenzaron a incluir cambios en sus portales de información sobre el coronavirus que se debían reseñar. Por tanto, se debe apuntar, en primer lugar, esa evolución. Un ejemplo de este desarrollo es el de España, que en un principio publicaba gran parte de los datos en PDF y a mediados de mayo ya permitía descargarlos en formatos reutilizables. Aun así, este país siguió teniendo diversos documentos en PDF, siendo estos elementos preferiblemente evitables por la dificultad a la hora de reutilizarlos (Cabezas Mardones, 2014). Destacó también la mejoría en el repositorio de datos chileno, que fue muy completo en la segunda evaluación.

Así, en la segunda codificación se hallaron diferencias notables entre las distintas páginas web. En este sentido, los países que registraron un peor resultado fueron Panamá y Portugal (con 26 puntos en total). Chile y Ecuador, por otro lado, fueron los países con un mejor resultado (36), seguidos de México (34), Colombia, Perú y Brasil (33), Costa Rica, España (30) y Uruguay y Argentina (28). Se puede observar el orden de los países en el siguiente gráfico: 


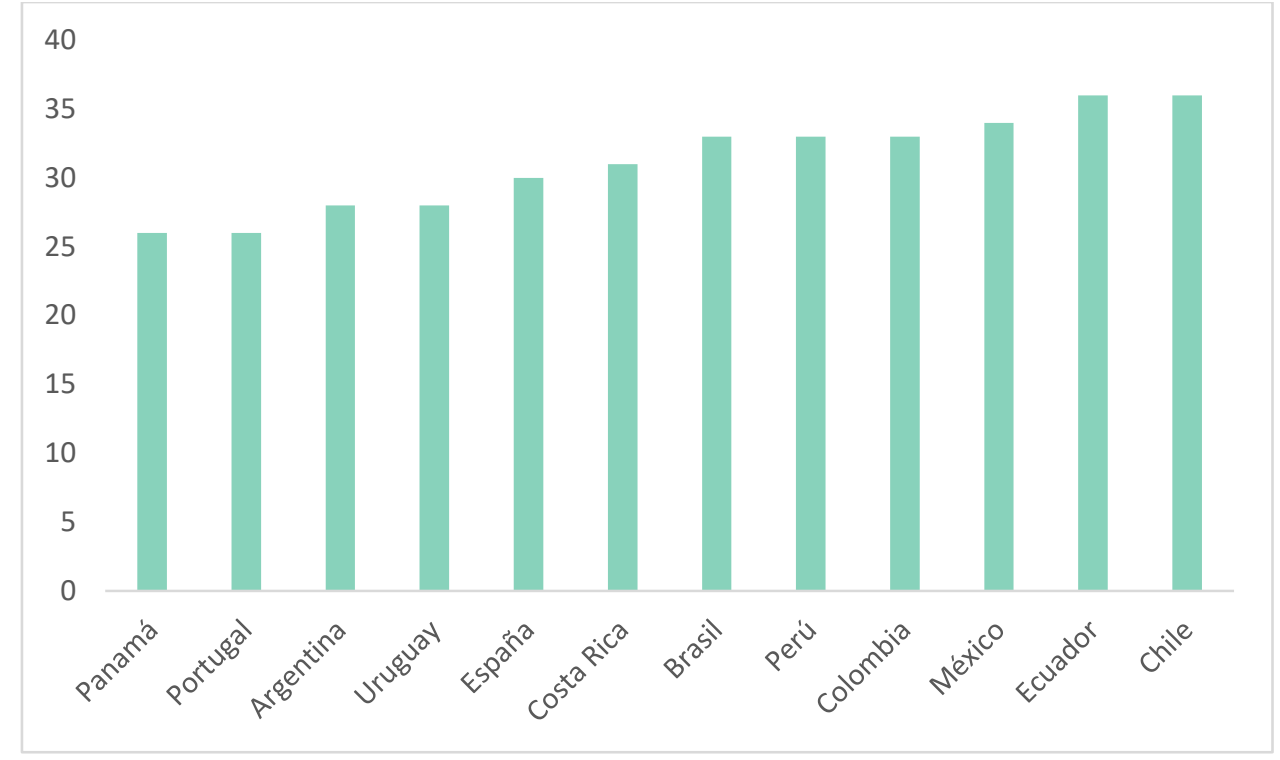

Gráfico 1. Transparencia de los portales de coronavirus de los países analizados

Fuente: elaboración propia

Aunque de forma general las instituciones obtuvieron calificaciones aceptables en cuanto a datos abiertos, se detectaron numerosas deficiencias de gran importancia. De hecho, cabe destacar que este estudio no pretende establecer un ranking por países, sino averiguar los puntos fuertes y débiles de estos portales de transparencia. A lo largo de esta investigación, se realizó una labor de búsqueda exhaustiva que hace que los resultados sean relativamente positivos. Sin embargo, esta información fue en muchas ocasiones difícil encontrarla en las plataformas digitales, de forma que consideramos que el resultado obtenido es algo mejor de lo que debería si se tienen en cuenta las dificultades en la codificación. Creemos que la facilidad para encontrar la información también forma parte de la transparencia, así como la estructura y navegación en las webs.

Salvo Panamá, todos los países contaban en su página web con un apartado específico dedicado a la información sobre el COVID-19. Una de las principales deficiencias halladas fue que solo Perú publicó en su portal de transparencia los contratos realizados durante el periodo de emergencia sanitaria. Esto resulta de extrema gravedad, pues es fundamental informar a la ciudadanía del dinero que se está gastando y en qué en esta situación para rendir cuentas de la gestión de la pandemia.

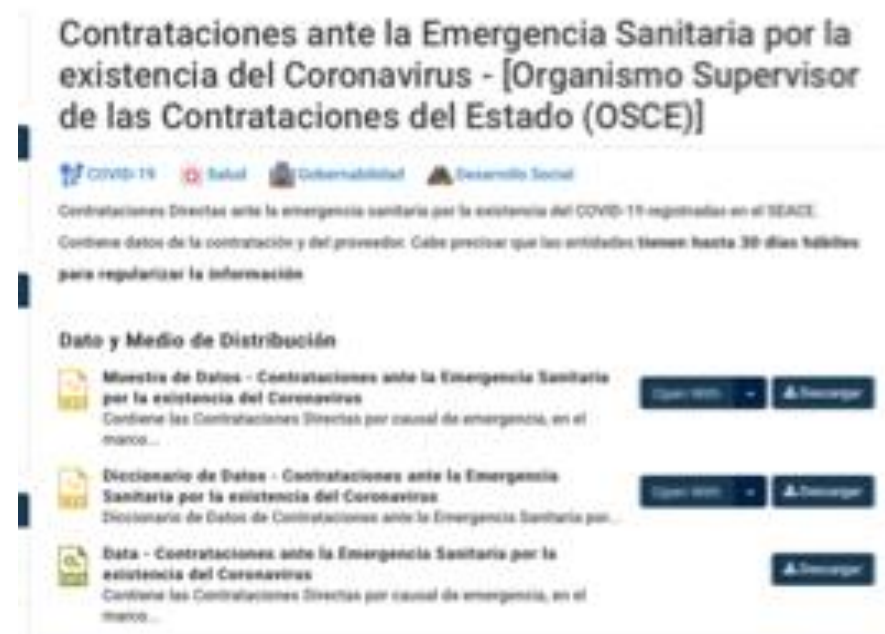

Figura 1: Portal del coronavirus de Perú

Fuente: https://www.datosabiertos.gob.pe/dataset/contrataciones-ante-la-emergencia-sanitaria-porla-existencia-del-coronavirus-organismo 
En esta misma línea, también Perú fue uno de los escasos países, junto a Brasil y Chile (este último solo de forma parcial), que publicaron información sobre el material comprado para hacer frente a la crisis sanitaria. De nuevo, se ve como algo muy negativo que los países no compartan esta información, pues la ciudadanía merece saber en qué se está gastando su dinero.

Observamos que los países se esforzaron especialmente por ofrecer información básica, como datos sobre la patología (síntomas), recomendaciones de prevención para la población y las principales medidas tomadas por los gobiernos. Eso sí, existen importantes diferencias entre unos y otros. En el apartado de medidas tomadas, por ejemplo, Portugal simplemente resumió las medidas, mientras que Perú, además de la información por secciones en la página principal, publicaron diariamente las acciones del gobierno.

Exceptuando a Panamá y Costa Rica, todos los gobiernos disponían de una sección de preguntas frecuentes, que puede resultar de mucha utilidad en una crisis como esta.

En otros datos hubo menos uniformidad entre los países, como en la publicación de recomendaciones para personas afectadas (siete lo publicaron y otros dos de forma parcial), así como la información sobre trabajadores afectados y las medidas tomadas en este sentido (cinco países no lo hicieron y uno solo de forma parcial). Esto llama la atención, pues es probablemente uno de los temas que más interés despierte en la población, al haberse producido la mayor subida del desempleo a nivel global desde que se tienen registros ${ }^{2}$.

Todos los países incluidos en este estudio contaron con un repositorio de datos sobre la propagación del virus. Hubo cuatro países que no permitían descargar los datos en un formato reutilizable, algo que reduce en gran medida la utilidad de los datos y la capacidad de la ciudadanía y de los profesionales de usarlos para crear nuevos contenidos. Aunque la mayoría sí publicó datos en formatos reutilizables, se debe destacar la necesidad de que todos cumplan con este deber. Este análisis planteaba que lo ideal sería que los datos se actualizaran dos veces al día, algo que solo se hizo en el portal argentino, donde se publicaba un breve informe -algo escaso y en formato PDF- por la mañana y otro por la tarde.

En estos repositorios, todos los estados publicaron el número de fallecimientos y los datos por regiones. Casi todos los países (salvo Argentina) publicaron también los datos de personas ingresadas, de personas recuperadas (salvo Argentina y Perú) y las edades afectadas (Panamá y Uruguay no lo hicieron, y Costa Rica y Perú, solo de forma parcial). En este último aspecto, hubo diferencias entre unos países y otros. La mayoría publicaban los grupos de edad afectados, mientras que otros desglosaban cada dato con la edad.

Solo siete de los doce países analizados publicaron el número de pruebas de detección del virus realizadas, así como las pruebas positivas y negativas. Subrayamos que algunos países, como Ecuador, diferenciaron entre unas pruebas diagnósticas y otras, como se puede ver a continuación.

\footnotetext{
2 RTVE (2020). La OCDE advierte de una escalada "sin precedentes" de la tasa de paro en abril por el coronavirus. Fuente: $\quad$ https://www.rtve.es/noticias/20200513/ocde-paro-espana-advierte-aumento-paro-sin-precedentes-mundialabril/2013991.shtml
} 


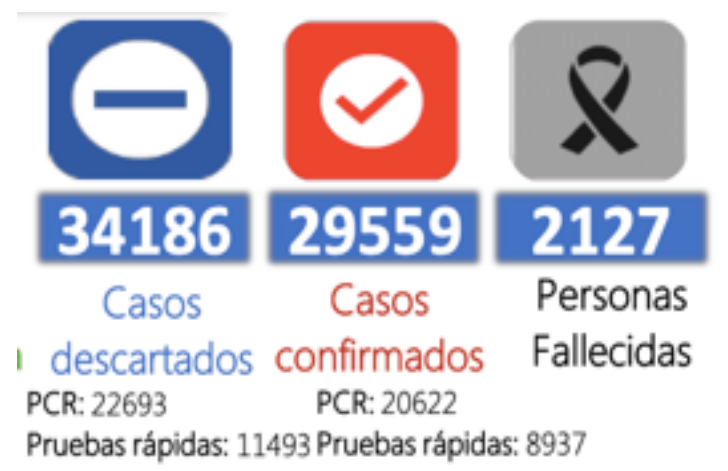

Figura 2: Portal del coronavirus de Ecuador

Fuente: https://www.salud.gob.ec/wp-content/uploads/2020/05/INFOGRAFIANACIONALCOVID19-COE-NACIONAL-10052020-08h00.pdf

Solamente Ecuador y Chile compartieron los datos sobre altas hospitalarias. Este es un dato muy importante a la hora de conocer los aspectos positivos de la evolución de la pandemia. No solo es necesaria, como se ha destacado antes, la cifra de personas recuperadas, sino también de aquellas que han estado hospitalizadas, pues permite comprender el desarrollo de los casos más graves.

El material gráfico fue considerado de especial relevancia en esta investigación, pues las infografías pueden ser muy útiles conocer la extensión del virus. En todos los portales se pudo hallar un mapa de infección interactivo. Excepto Perú y Uruguay, todos los países contaron también con un gráfico de la curva de infección. Casi todos los países, además, incluyeron otros gráficos interesantes entre los que destacamos los siguientes:

- Gráficos por edad y sexo (infectados y número de fallecidos).

- Mapas exhaustivos por municipios e incluso por distritos.

- Evolución de la propagación del virus por zonas.

Hemos señalado anteriormente que el objetivo de este trabajo de investigación es indicar las principales insuficiencias, algunas ya mencionadas en este epígrafe. Otras carencias detectadas fueron la publicación excesiva de documentos en formato PDF, como en España y Costa Rica, o la inexistencia de una sección específica sobre la pandemia en Panamá, que hizo difícil hallar gran parte de la información recabada en este análisis.

Destacamos a continuación una serie de buenas prácticas halladas en la codificación que fueron valoradas de forma positiva:

- Apartado de bulos relacionados con el COVID-19 (Brasil, Ecuador, México, Colombia).

- Publicación en México de secciones específicas de gran interés, como medidas con perspectiva de género, información para niños y mayores, mitos y realidades, información para pueblos indígenas, artículos científicos y apartados de cultura, de bioética y de salud mental.

- Ecuador creó un memorial online para las víctimas mortales, un homenaje que llamó la atención.

- Test de autoevaluación (Ecuador, Argentina)

- Información sobre las medidas higiénicas y de limpieza recomendadas en diferentes circunstancias (Argentina).

- Perú ofrecía un espacio para participar y para que los usuarios indicaran posibles mejoras de la página web.

- Colombia disponía de una sección de convocatoria pública para proveedores de material. 


\subsection{Medios de comunicación}

Respecto a los medios de comunicación, los resultados en lo referente a sus mecanismos de transparencia y participación de los usuarios en los contenidos relacionados con el COVID-19 es significativamente peor que el de las páginas webs institucionales de los gobiernos.

De los 24 medios de comunicación analizados, solo uno de ellos llega a la mitad de la puntuación máxima que podía obtenerse en los items de la codificación (puntuación máxima de 26), es el caso del diario La Nación de Costa Rica (16). Cuatro medios digitales rozan el aprobado con 12 puntos: Público (Portugal), Biobio (Chile), Emol (Chile) y La República (Perú). En el lado contrario, los medios que obtuvieron una peor puntuación (0), ya que no se encontró presencia de ninguno de los items codificados en sus páginas web, fueron: La República (Ecuador), Vistazo (Ecuador) y El País (Uruguay). Estos tres medios no contaban con sección especial sobre el COVID-19, no realizaron ningún tipo de trabajo de datos o infográfico y no aplicaron prácticas de transparencia ni participación respecto a los contenidos relacionados con la pandemia.

En el siguiente gráfico se muestra el orden de calificación obtenido en los medios de comunicación analizados:

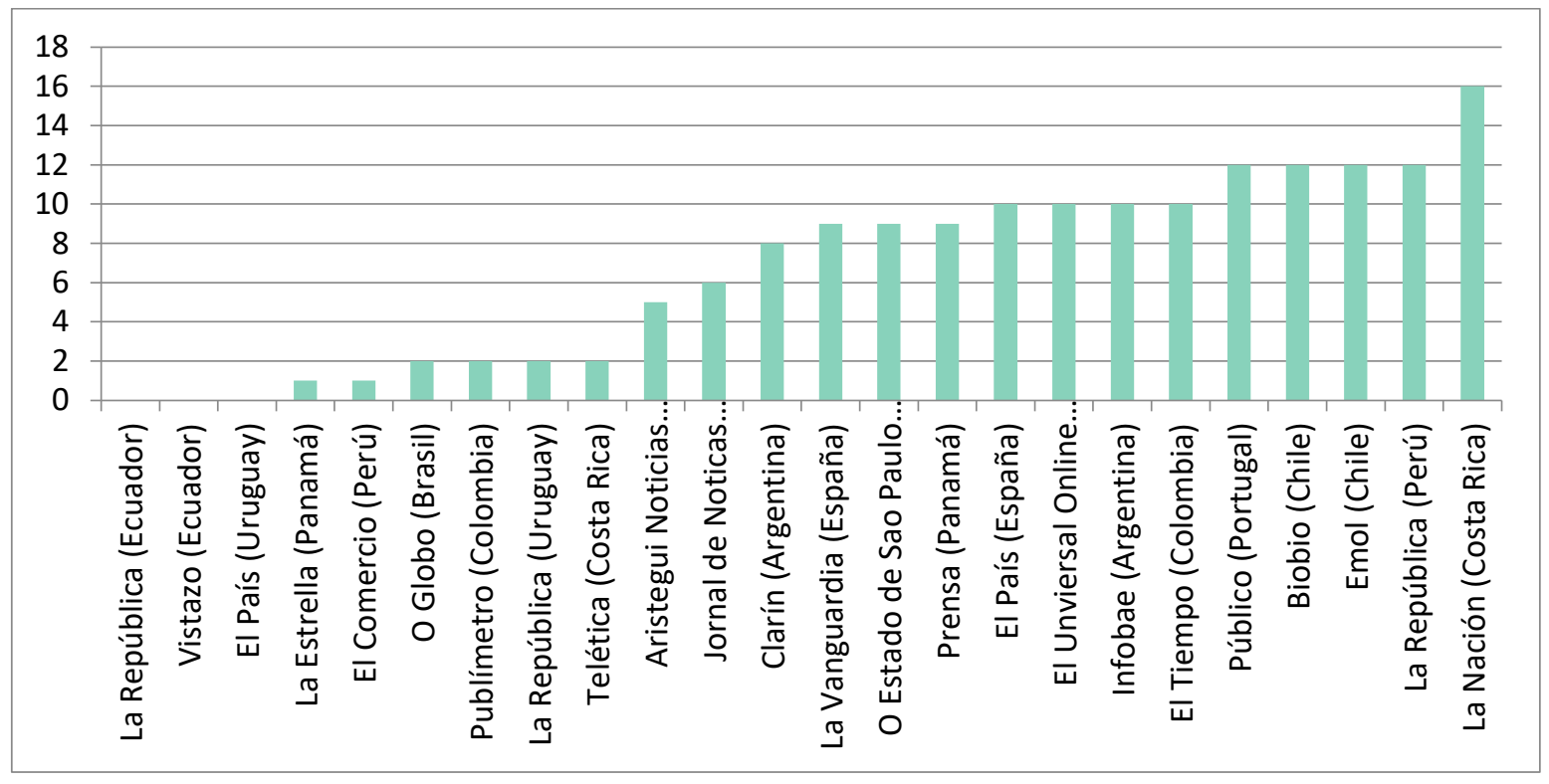

Gráfico 2: Apertura de los medios de comunicación

Fuente: elaboración propia

En general la mayoría de los medios iberoamericanos analizados elaboraron una sección especial sobre el Coronavirus destacada en su portada. Los únicos tres medios que no incluyeron una sección diferente fueron La República y Vistazo (Ecuador) y El País (Uruguay). En el caso de La Estrella (Panamá) y El Comercio (Perú), la sección era únicamente un enlace a las noticias que tenían una etiqueta relacionada, pero no se trataba de una sección diferenciada del resto de contenidos. El resto de medios analizados sí contaba con un apartado específico destacado dedicado al COVID-19.

En cuanto al periodismo de datos y la elaboración de material infográfico, fue el apartado donde, en general, los medios iberoamericanos más destacaron en la codificación. Solo 9 de los 24 medios analizados no realizaron ningún tipo de periodismo de datos ni incluyeron gráficos o infografías en sus contenidos. Los medios que no incluyeron estas prácticas son los mencionados en el párrafo anterior y $O$ Globo (Brasil), Publímetro (Colombia), La República (Uruguay) y Telética (Costa Rica). En el caso de Aristegui Noticias (México), tampoco se desarrolló periodismo de datos propio y 
el material gráfico más destacable que se incluía fue una inserción del mapa desarrollado por la Escuela de Ingeniería de la Universidad Johns Hopkins de Estados Unidos y los gráficos de barras con datos demográficos desarrollados por el gobierno, pero no incluyó material de elaboración propia.

El resto de medios todos desarrollaron material propio utilizando técnicas de periodismo de datos y elaboraron mapas interactivos y curvas de infección. A excepción de Jornal de Noticias (Portugal), que solo desarrolló un contenido infográfico estático que incluía un mapa no interactivo y otros gráficos de barras, pero no la curva de infección.

Algunos medios de comunicación desarrollaron, en el contexto del periodismo de datos, una amplia variedad de infografías y gráficos dentro de sus secciones dedicadas al COVID-19. Se incluyeron, además de mapa interactivo y curva de infección, gráficos con datos demográficos de la población afectada, mapas y gráficos de otros países distintos al del diario analizado, datos desglosados por regiones del país e incluso gráficos con curvas de valor del dólar mexicano y del petróleo ( $E l$ Universal Online, México).

Además, algunos medios de comunicación desarrollaron contenidos infográficos adicionales, como cronologías de la pandemia, infografías con los síntomas del virus, ilustraciones sobre prevención, o cómo desinfectar superficies y otros contenidos de tipo divulgativo.

En el análisis llama la atención que solo 1 de los 24 medios analizados en el estudio elaborase contenidos de fact-checking relacionados con el COVID-19, a pesar de que la divulgación de información deliberadamente falsa se ha convertido en un problema sanitario durante esta pandemia (Salaverria et al., 2020). Es especialmente reseñable que ningún medio colombiano aplicó contenidos específicos de fact-checking, pese a que en el análisis de la web publicada por su Gobierno sí se incluía una sección para desmentir bulos. El único medio que realizó este tipo de prácticas fue $L a$ Nación (Costa Rica), a través de una sección titulada \#NoComaCuento, que desmentía de forma periódica durante los meses de marzo y abril los bulos relacionados con la pandemia, a través de publicaciones textuales y podcast.

\section{DCOMACUENTO \\ \#NoComaCuento: Recuento de las mentiras sobre el nuevo coronavirus que circulan en Costa Rica}

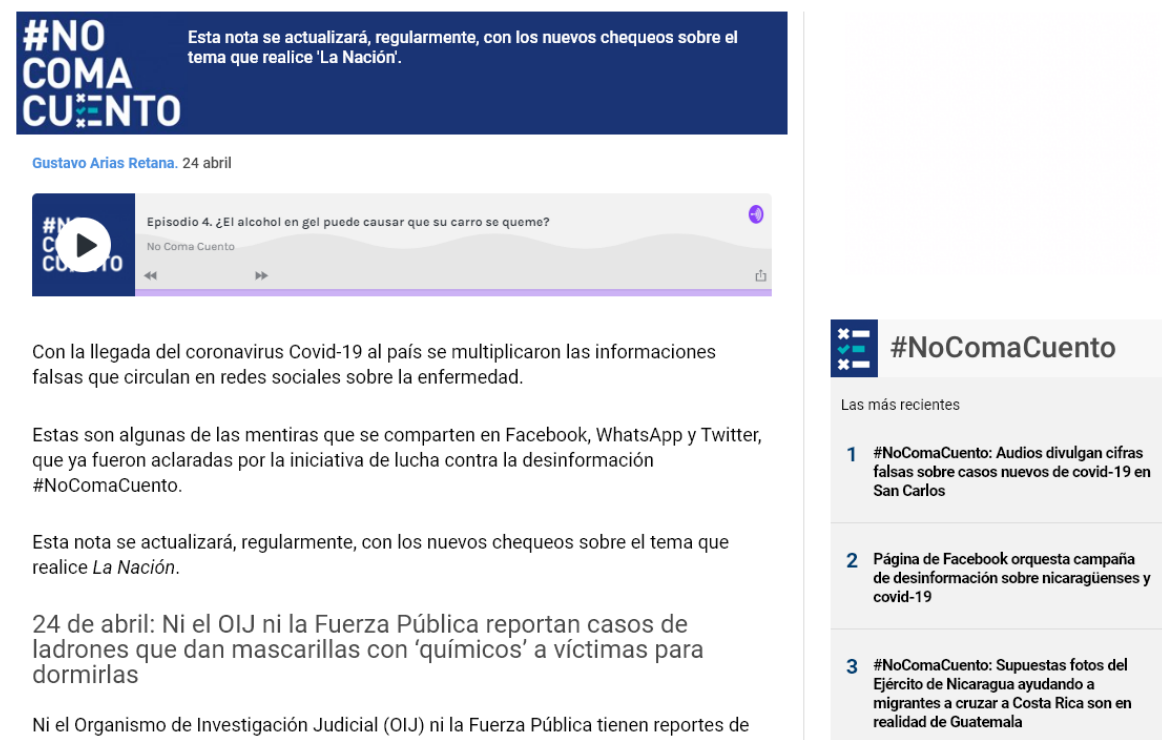

Figura 2: Sección contra los bulos en La Nación

Fuente: https://www.nacion.com/no-coma-cuento/nocomacuento-recuento-de-las-mentiras-sobreel/PDZBAAQCAVBMJIR6GQZZ5YWZSI/story/ 
Respecto a la parte de transparencia, solo se detectaron tres medios que realizaran buenas prácticas en este sentido, fueron los casos de El País (España), Estadao do Sao Paulo (Brasil) y La Nación (Costa Rica). En el caso de El País, se publicó la metodología utilizada en sus trabajos de periodismo de datos en varios reportajes. A través de textos divulgativos explicaban a los usuarios cómo elaboraban los gráficos de curva de infección o aportaban información sobre las métricas utilizadas. Los otros dos medios, Estadao do Sao Paulo y La Nación, publicaron en abierto las bases de datos utilizadas para la elaboración de sus contenidos, de tal forma que cualquiera de sus lectores podía descargarla.

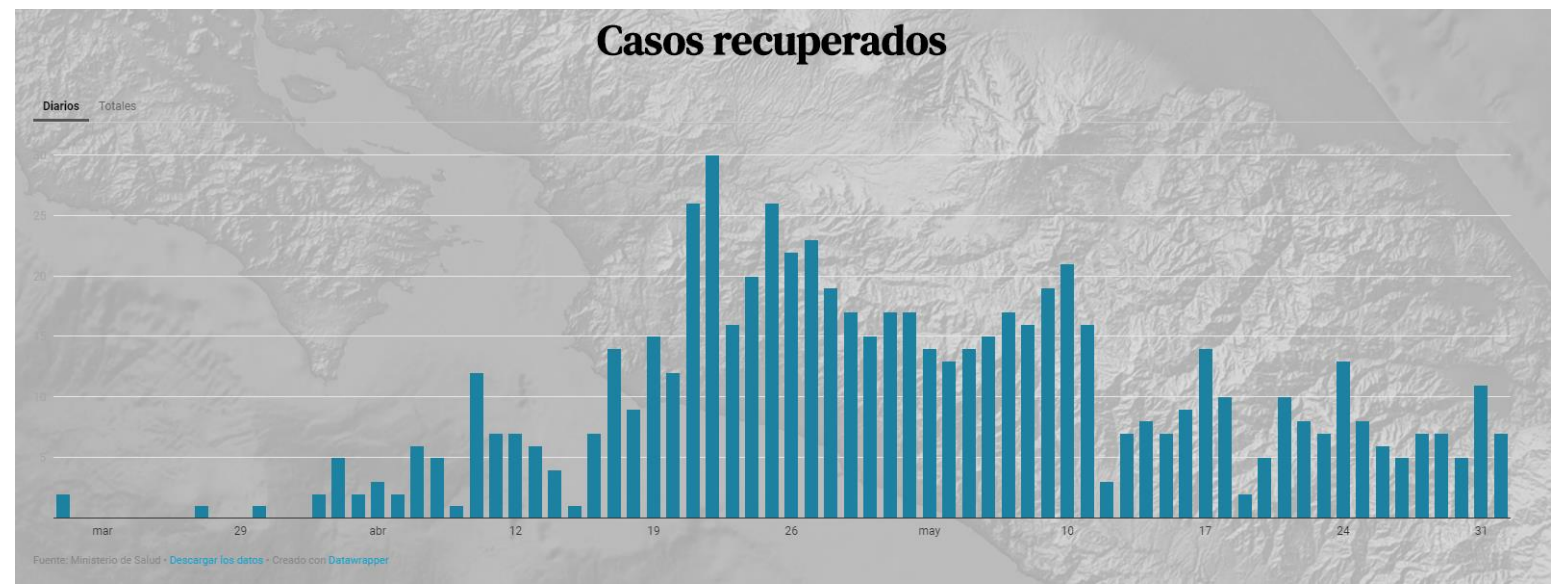

Figura 3: Sección de datos de La Nación

Fuente:

https://www.nacion.com/gnfactory/especiales/2020/Covid19/index.html\#utm_source=website\&utm $\underline{\text { medium }=\text { marilyn\&utm_campaign=marilyn }}$

Ninguno de los otros medios analizados que realizaba periodismo de datos aportó información sobre la metodología utilizada o publicó las fuentes y bases de datos utilizadas de forma accesible. La mayoría solo indicaban la fuente de forma textual (por ejemplo, Fuente: elaboración propia o Fuente: Gobierno de Perú), sin enlazar a la base de datos original o indicar otro tipo de información adicional.

Por último, en lo referente al análisis de participación y colaboración, ninguno de los medios analizados contó con canales de participación específicos del COVID-19 para los usuarios, ni aportó vías de colaboración para la elaboración de contenidos con el público. Tampoco se detectó ningún contenido elaborado de forma colaborativa con otros medios de comunicación o entidades en los medios de comunicación analizados, si bien se tiene conocimiento de algunos casos de colaboración que no han sido incluidos en este estudio.

Los resultados de los medios analizados por países solo muestran en algunos casos igualdad en las puntuaciones obtenidas en relación al país de origen: es el caso de los dos medios de Ecuador (que obtuvieron la peor puntuación, pese a que su Gobierno consiguió la segunda mejor calificación en el análisis presentado en el epígrafe anterior), el de los medios chilenos, que obtuvieron la misma puntuación de 12, rozando el aprobado, o los medios de Uruguay, que, pese a no tener la misma puntuación (0 El País y 2 La República). se encuentran entre los medios con los índices más bajos. El resto de diarios analizados no muestran una relación determinante entre la puntuación obtenida y su país de origen. 


\section{Conclusiones}

La crisis del coronavirus ha dejado una huella en los portales de transparencia de todo el mundo. En este artículo, hemos estudiado la información disponible en los portales digitales de 12 países de Iberoamérica (España, Brasil, Portugal, Chile, Ecuador, Panamá, México, Perú, Argentina, Colombia, Uruguay y Costa Rica). Si bien todos los países obtuvieron un resultado aceptable en el cómputo global, este análisis no pretendía establecer un ranking por países, sino destacar los puntos fuertes y las carencias de estos portales. De hecho, muchos países obtuvieron un buen resultado a pesar de que fue muy complicado encontrar algunos datos por la accesibilidad de las páginas web.

Se cumple así la primera hipótesis, que señalaba que los gobiernos presentarían deficiencias en su transparencia sobre el coronavirus. Una de las principales deficiencias fue que los gobiernos no publicaron (salvo escasas excepciones) los contratos y las compras realizadas relacionadas con la crisis sanitaria, datos de gran interés para la ciudadanía que permiten a los gobiernos rendir cuentas. Respecto a los repositorios de datos, estos solo se actualizaban una vez al día, casi ningún país publicaba la cifra de altas hospitalarias y fue mejorable la difusión de pruebas diagnósticas realizadas. También se debe desarrollar la posibilidad de permitir a los usuarios descargar el material en un formato reutilizable, algo que no todos los países hicieron.

Respecto a los medios de comunicación analizados, en general, se ha notado un interés por parte de la mayoría de medios en cubrir de forma específica la pandemia, y como resultado se muestra que 21 de los 24 medios analizados contaban con un apartado diferenciado en sus portadas dedicado al COVID-19. Sin embargo al hablar de prácticas relacionadas con el periodismo abierto, transparencia, participación y colaboración, los medios iberoamericanos suspenden de forma rotunda en el uso de estas prácticas.

Se confirma de esta forma la segunda hipótesis, que plantea medios de comunicación no han desarrollado el periodismo abierto durante la crisis del coronavirus para informar sobre la pandemia y hay escasos ejemplos de ello. Ninguno de los medios analizados aplicó estrategias de participación con los usuarios ni colaboración con otros medios y entidades y solo tres de los medios desarrollaron contenidos aplicando algún criterio de transparencia (en uno de los casos la publicación de la metodología de trabajo y en los otros dos la publicación en abierto de las bases de datos utilizadas).

Sin embargo, en lo referente al periodismo de datos sí podemos confirmar la tercera hipótesis que planteaba que en el contexto iberoamericano los medios de comunicación han practicado este tipo de estrategia para informar sobre el coronavirus. Solo 9 de los 24 medios analizados no realizaron ningún tipo de periodismo de datos, el resto aportaron de forma mayoritaria al menos algún mapa interactivo y la curva de infección, aunque en muchos casos ampliaron la cobertura con la elaboración de más gráficos relacionados con el tema. Una práctica que guarda relación con el uso de los portales de transparencia de los gobiernos ya que, al citar la fuente, muchos de ellos, además de la elaboración propia, referenciaban como fuente a las páginas web institucionales.

Realizados ambos estudios, se quiso comprobar la semejanza en los resultados entre el análisis de la transparencia institucional y la apertura mediática. Sin embargo, no se hallaron resultados relevantes. Como se observa en el siguiente gráfico, existen algunas coincidencias, como el resultado negativo de Uruguay y de los medios uruguayos y los resultados positivos de Chile y México y sus respectivos medios. Sin embargo, también hubo diferencias en el caso de Ecuador, que fue el más transparente en el análisis institucional y cuyos medios tuvieron resultados muy negativos, y Portugal, que obtuvo el peor resultado a nivel institucional, mientras que los medios portugueses recibieron mejores puntuaciones. Por tanto, no se observó ninguna relación entre el desarrollo de la transparencia institucional y la apertura mediática en los países y medios analizados. 
RLCS, Revista Latina de Comunicación Social, 78, 393-418

[Investigación] DOI: 10.4185/RLCS-2020-1482| ISSN 1138-5820| Año 2020

Tabla 2. Comparación entre la transparencia institucional de los países iberoamericanos y la apertura de sus medios de comunicación

\begin{tabular}{|c|c|}
\hline País & Total (44) \\
\hline Ecuador & 36 \\
\hline Chile & 36 \\
\hline México & 34 \\
\hline Brasil & 33 \\
\hline
\end{tabular}

\begin{tabular}{|c|c|}
\hline Perú & 33 \\
\hline \multicolumn{2}{|c|}{} \\
\hline Colombia & 33 \\
\hline \multicolumn{2}{|c|}{} \\
\hline Costa Rica & 31 \\
\hline
\end{tabular}

\begin{tabular}{|c|c|}
\hline España & 30 \\
\hline \multicolumn{2}{|c|}{} \\
\hline Argentina & 28 \\
\hline
\end{tabular}

\begin{tabular}{|c|c|}
\hline Uruguay & 28 \\
\hline \multicolumn{2}{|c|}{} \\
\hline Panamá & 26 \\
\hline
\end{tabular}

\begin{tabular}{|l|l|}
\hline Portugal & 26 \\
\hline
\end{tabular}

\begin{tabular}{|c|c|}
\hline Medios de comunicación & Total (24) \\
\hline La Nación (Costa Rica) & 16 \\
\hline Público (Portugal) & 12 \\
\hline Biobio (Chile) & 12 \\
\hline Emol (Chile) & 12 \\
\hline La República (Perú) & 12 \\
\hline El País (España) & 10 \\
\hline El Unviersal Online (México) & 10 \\
\hline Infobae (Argentina) & 10 \\
\hline El Tiempo (Colombia) & 10 \\
\hline La Vanguardia (España) & 9 \\
\hline O Estado de Sao Paulo (Brasil) & 9 \\
\hline Prensa (Panamá) & 9 \\
\hline Clarín (Argentina) & 8 \\
\hline Jornal de Noticas (Portugal) & 6 \\
\hline Aristegui Noticias (México) & 5 \\
\hline O Globo (Brasil) & 2 \\
\hline Publímetro (Colombia) & 2 \\
\hline La República (Uruguay) & 2 \\
\hline Telética (Costa Rica) & 2 \\
\hline La Estrella (Panamá) & 1 \\
\hline El Comercio (Perú) & 1 \\
\hline La República (Ecuador) & 0 \\
\hline Vistazo (Ecuador) & 0 \\
\hline El País (Uruguay) & 0 \\
\hline
\end{tabular}

Fuente: elaboración propia

Responderemos a continuación las preguntas de investigación:

\section{1. ¿Hay diferencias entre los países europeos y los americanos?}

Podemos afirmar que sí se detectaron mejores resultados en los portales americanos, respecto a los europeos. En este sentido, Portugal tuvo una de las webs más deficientes, mientras que España fue el quinto peor. En cuanto a los medios de comunicación no se detectan diferencias reseñables entre los diarios de origen europeo y los pertenecientes a Latinoamérica.

\section{2. ¿Los países con más personas infectadas han presentado diferencias respecto al resto?}

No se identificó ninguna relación entre la cifra de personas infectadas en el país y el desarrollo de los portales de transparencia. En el siguiente gráfico se puede ver la puntuación obtenida en el análisis de las webs (en orden descendente) junto al número de infectados de cada país y la posición que 
RLCS, Revista Latina de Comunicación Social, 78, 393-418

[Investigación] DOI: 10.4185/RLCS-2020-1482| ISSN 1138-5820| Año 2020

ocuparía en un ranking de la extensión del virus en estos países, donde no se observa ninguna relación.

Tabla 3. Comparación entre la transparencia de los países y la incidencia del COVID-19

\begin{tabular}{|c|c|c|}
\hline País & Total $(44)$ & $N^{\text {o }}$ infectados $(20 / 05 / 2020)$ \\
\hline Ecuador & 36 & $34151\left(6^{\circ}\right)$ \\
\hline Chile & 36 & $49579\left(5^{\circ}\right)$ \\
\hline México & 34 & $54346\left(4^{\circ}\right)$ \\
\hline Brasil & 33 & $271885\left(1^{\circ}\right)$ \\
\hline Perú & 33 & $99483\left(3^{\circ}\right)$ \\
\hline Colombia & 33 & $16935\left(8^{\circ}\right)$ \\
\hline Costa Rica & 31 & $232037\left(2^{\circ}\right)$ \\
\hline España & 30 & $8809\left(10^{\circ}\right)$ \\
\hline Argentina & 28 & $738\left(12^{\circ}\right)$ \\
\hline Uruguay & 28 & $9867\left(9^{\circ}\right)$ \\
\hline Panamá & 26 & $29660\left(7^{\circ}\right)$ \\
\hline Portugal & 26 & \\
\hline
\end{tabular}

Fuente: elaboración propia

En cuanto a los medios de comunicación, tampoco se ha identificado ninguna relación entre la cifra de las personas con las puntuaciones obtenidas en los diferentes apartados, ya que en el caso de algunas localizaciones los propios medios de cada país presentaron puntuaciones muy diferentes.

\section{3. ¿Qué tipo de datos comparten los gobiernos para informar sobre el coronavirus?}

Se puede resumir que los portales analizados compartieron información básica sobre el virus, como los síntomas, las recomendaciones esenciales para la población y las medidas tomadas por cada gobierno. Respecto a la extensión de la pandemia, fueron especialmente transparentes con la cifra de personas fallecidas y con los datos por regiones. Además, todos los países trataron de hacer comprensible esta información a través de un mapa interactivo de la infección.

4. ¿Se fomenta de alguna forma la participación y la reutilización de los datos?

La promoción de la reutilización es uno de los aspectos más desiguales en el estudio de los portales de transparencia, pues más de la mitad sí publicaron los datos en un formato accesible, pero aun así diversos gobiernos no lo hicieron. Además, de forma general se hallaron demasiados documentos en formato PDF en las webs. Fue especialmente llamativo el caso de Costa Rica, pues prácticamente toda la información que publicaba se hallaba en PDF y hubo que buscar cada elemento analizado en estos documentos.

En cuanto a la participación, solamente el de Perú disponía de una sección en la que se podía participar y ofrecer mejoras de la página web.

5. ¿Promueven los medios digitales la transparencia y la participación de alguna forma? 
En los medios de comunicación el fomento de la participación de los usuarios en el contexto del COVID-19 es nulo, ya que no se encontró ninguna iniciativa en la que el público pudiera aportar a ningún tipo de contenido. En cuanto a la reutilización de datos, por parte de los diarios tampoco se muestra interés en mostrar apertura, ya que solo dos de los diarios analizados publicaron de forma abierta las bases de datos utilizadas.

Se debe indicar que este estudio parte de una limitación, que es el momento de realizarlo. Aunque se codificó el trabajo en una fecha en la que la pandemia ya estaba muy avanzada, es posible que algún país realizara a posteriori algún cambio a mejor o a peor. Es por ello que la codificación se realizó en dos ocasiones, al principio de la pandemia y en mayo, cuando ya había avanzado, de modo que el estudio contara con los avances realizados por las instituciones y los medios de comunicación.

En este sentido, la codificación se repitió porque se detectó una mejoría en los portales de datos. Estos cambiaron a lo largo de la crisis sanitaria y evolucionaron notablemente respecto a su planteamiento inicial. Se incluyeron más datos y gráficos en estas páginas web. Por tanto, se puede afirmar que el tiempo hizo que se replantearan la estructura y la información que se debe dar a la ciudadanía. Además, este pretende ser un primer estudio exploratorio de los primeros meses de la pandemia. La realidad es más compleja a medida que avanza el tiempo, por lo que se requiere una mayor profundización en próximos estudios.

Se debe destacar que, al haber sido un fenómeno repentino, no existe una normativa, ni una referencia anterior que pudiera guiar a las instituciones sobre la mejor forma de actuación, de forma que los gobiernos improvisaron, actuaron intuitivamente y observando lo que hacían los de su alrededor. Esto hizo que aquellos países en los que hay una menor cultura de la transparencia se pudieran ver más afectados en ese sentido. No obstante, al detectarse cierta evolución en los portales de transparencia, se puede prever que una emergencia como esta ha podido servir a los gobiernos para hacer ver la necesidad de contar con portales de datos correctamente actualizados y publicar en formatos reutilizables. Asimismo, puede resultar de gran utilidad conocer las necesidades informativas de la ciudadanía para publicar datos que, aunque no sean obligatorios, se deben difundir.

Los medios de comunicación, por su parte, han tenido que adaptarse rápidamente a esta situación y utilizar los datos provistos por los gobiernos a través de sus portales. Esto se ha traducido en la práctica del periodismo de datos y de visualizaciones de distinto tipo en los medios de comunicación. No obstante, los medios no aprovecharon este periodo para favorecer una mayor transparencia de sus metodologías y sus fuentes, ni para fomentar la colaboración y la participación ciudadana. Cabe indicar que este estudio analiza dos medios de comunicación de cada país, de forma que es una primera muestra del panorama de cada país, que es más amplio y variado, de modo que existen ejemplos interesantes de otros medios que han llevado a cabo propuestas innovadoras y abiertas. Este es uno de los límites de esta investigación, que se pretende ampliar próximamente con más ejemplos mediáticos de relevancia.

La trágica pandemia que ha sacudido al planeta ha demostrado la necesidad de desarrollar la transparencia para que los gobiernos estén a la altura en situaciones de emergencia como esta y los medios puedan beneficiarse de su transparencia para desarrollar prácticas periodísticas abiertas. 


\section{Bibliografía}

Anderson, C. W., Bell, E., Shirky, C. (2013). Periodismo postindustrial. Adaptación al presente. eCícero.

Amazeen, M. A. (2017) Journalistic interventions: The structural factors affecting the global emergence of fact-checking, Journalism: Theory, Practice \& Criticism. https://doi.org/10.1177/1464884917730217.

Bachmann, I., \& Harlow, S. (2012). Interactividad y multimedialidad en periódicos latinoamericanos: avances en una transición incompleta. Cuadernos de información, (30), 41-52. https://doi.org/10.7764/cdi.30.421

Barón, A. (06/04/2020) Coronavirus: transparencia para una mejor gestión de la crisis. La Vanguardia. Recuperado de: https://www.lavanguardia.com/opinion/20200406/48327327461/coronavirus-transparencia-mejorgestion-crisis.html.

Barredo-Ibáñez, D., \& Díaz-Cerveró, E. (2017). La interactividad en el periodismo digital latinoamericano. Un análisis de los principales cibermedios de Colombia, México y Ecuador (2016). Revista Latina de Comunicación Social, (72), 273-294. https://doi.org/10.4185/RLCS$\underline{2017-1165}$

Boletín Oficial del Estado (2013) Ley 19/2013 de Transparencia, Acceso a la Información Pública y Buen Gobierno.

Cabezas-Mardones, C. (2014). Transparencia activa: Gestión de documentos electrónicos y datos en Chile. Serie Bibliotecología y Gestión de Información, (93).

Campos Domínguez, E., y Redondo García, M. (2015) Meta periodismo y transparencia informativa en el periodismo del siglo XXI. OBETS: Revista de Ciencias Sociales, 10(1), 185-209. https://doi.org/10.14198/OBETS2015.10.1.07

Caridad Sebastián, M. and Martínez Cardama, S. (2016) Gobierno y Parlamento abierto: la participación ciudadana en el tratamiento y visualización de la información pública, Revista Interamericana de Bibliotecología, 39(1), 57-68. https://doi.org/10.17533/udea.rib.v39n1a07.

Cerrillo-i-Martínez, A. (2012). The Reuse of Public Sector Information in Europe and Its Impact on Transparency, European Law Journal, 18(6), 770-792. https://doi.org/10.1111/eulj.12003.

CLAD (2008) Carta Iberoamericana de Calidad en la Gestión Pública. Recuperado de: https://clad.org/wp-content/uploads/2020/07/Carta-Iberoamericana-de-Calidad-en-la-GestionPublica-06-2008.pdf

Cotino Hueso, L. (2017) El avanzado reconocimiento y regulación del derecho de acceso a la información pública y la transparencia en Iberoamérica (y su brecha con la realidad), Cuadernos Manuel Giménez Abad, 14, 211-222. 
Díaz-Noci, J. (2010). Medios de comunicación en internet: Algunas tendencias. El Profesional De La Información, 19 (6), 561. https://doi.org/10.3145/epi.2010.nov.01

EFE (05/04/2020). La Policía alerta de la creación de 1,5 millones de cuentas en redes sociales para "manipular" sobre el coronavirus. Eldiario.es. Recuperado de: https://www.eldiario.es/sociedad/millon-cuentas-difunden-noticias-COVID19_0_1013498870.html.

Escudero, J. (25/03/2020). Más lío con las cifras oficiales: los datos de las CCAA no son homogéneos entre sí. El Confidencial. Recuperado de: https://www.elconfidencial.com/espana/2020-03-25/coronavirus-cifras-oficiales-comunidadesautonomas_2515836/.

Ford, E., Boyd, A., Bowles, J. K., Havard, A., Aldridge, R. W., Curcin, V., \& Sperrin, M. (2019). Our data, our society, our health: A vision for inclusive and transparent health data science in the United Kingdom and beyond. Learning health systems, 3(3), e10191.

García-Altés, A. and Barba, G. (2013) Transparencia en los resultados de la sanidad pública: el ejemplo de la Central de Resultados del sistema sanitario catalán', Auditoria Publica, 61(1), 4552.https://asocex.es/transparencia-en-los-resultados-de-la-sanidad-publica-el-ejemplo-de-lacentral-de-resultados-del-sistema-sanitario-catalan

Gray, J., Chambers, L., \& Bounegru, L. (2012). The data journalism handbook: How journalists can use data to improve the news. O'Reilly Media, Inc.

Huijboom, N. and Broek, T. Van Den (2011) Open data : an international comparison of strategies, European Journal of ePractice, 12(March/ April 2011), 1-13. https://doi.org/1988-625X.

Kemp, S. (2019). Municipal transparency: moving beyond intrinsic value and the corruption antidote. La Criminología que viene. Resultados del I Encuentro de Jóvenes Investigadores en Criminología. REJIC.

Ley orgánica de transparencia y acceso a la información pública de Ecuador. Recuperado de: https://www.educacionsuperior.gob.ec/wp-content/uploads/downloads/2014/09/LOTAIP.pdf

Lewis, S. C., \& Usher, N. (2013). Open source and journalism: Toward new frameworks for imagining news innovation. Media, culture \& society, 35(5), 602-619. https://doi.org/10.1177/0163443713485494

López-García, X., Toural, C. and Rodríguez-Vázquez, A.-I. (2016) Software, estadística y gestión de bases de datos en el perfil del periodista de datos, El Profesional de la Información, 25(2), 286. doi: https://doi.org/10.3145/epi.2016.mar.16.

Lotero-Echeverri, G.; Romero-Rodríguez, L. M.; Pérez-Rodríguez, M. A. (2018). Fact-checking vs. Fake news: Periodismo de confirmación como recurso de la competencia mediática contra la desinformación. index.comunicación, 8(2), 295-316.

Lourenço, R. P. (2015) An analysis of open government portals: A perspective of transparency for accountability, Government Information Quarterly. Elsevier Inc., 32(3), 323-332.: https://doi.org/10.1016/j.giq.2015.05.006. 
Maldita (02/04/2020). Los datos del brote de coronavirus que el Gobierno no publica. Maldita. Recuperado de: https://maldita.es/malditodato/2020/04/02/datos-coronavirus-gobierno-nopublical.

Manfredi-Sánchez, J.-L. (2017). Horizontes de la información pública. El Profesional de La Información, 26(3), 353. https://doi.org/10.3145/epi.2017.may.01

Palomares Herrera, M. (2017). Estudio comparado sobre transparencia y derecho de acceso en el ámbito internacional y su influencia en España. Revista de Derecho, 6, 123-153.

Paniagua Vázquez, A., \& Morales Zamorano, M. A. (2017). Transparencia, Accountability y Gobierno Abierto: Comparación de los municipios de Hermosillo, Sonora y Juárez, Chihuahua desde la acreditación ciudadana de la función contralora de los municipios en México. Revista Estudio \& Debate, 24(2), 153-167. https://doi.org/10.22410/issn.1983-036X.v24i2a2017.1243

Paucar Carrión, K. and Coronel-Salas, G. (2019) Laboratorios : un recurso para la innovación periodística, Revista Iberica de Sistemas e Tecnologias de Informaçao, 20, pp. 477-490.

Ruijer, E. et al. (2019). The Politics of Open Government Data: Understanding Organizational Responses to Pressure for More Transparency, American Review of Public Administration. doi: https://doi.org/10.1177/0275074019888065.

Ruiz-Rico Ruiz, C. (2019). Análisis comparativo de la legislación iberoamericana en materia de transparencia y derecho de acceso a la información. Boletín mexicano de derecho comparado, 52(154), 255-283. http://dx.doi.org/10.22201/iij.24484873e.2019.154.14144

Salaverría, R., Buslón, N., López-Pan, F., León, B., López-Goñi, I., \& Erviti, M. C. (2020). Desinformación en tiempos de pandemia: tipología de los bulos sobre la Covid-19. El profesional de la información (EPI), 29(3).

Sampedro, V. (2015). El cuarto poder en red. Por un periodismo (de código) libre (Vol. 1). Ediciones Ciespal.

Toffler, A. (1980). The Third Wave. Nueva York (USA): Bantam Books.

Vivar, J. M. F. (2019). Inteligencia artificial y periodismo: diluyendo el impacto de la desinformación y las noticias falsas a través de los bots. Doxa Comunicación. Revista interdisciplinar de estudios de Comunicación y Ciencias Sociales, (29), 197-212. https://dialnet.unirioja.es/servlet/articulo?codigo $=7175495$

Vegas, X. R., De los Ríos, M. M., \& Anguiano, F. A. (2016). Transparencia informativa, autorregulación y participación del público: Mural. com, Rue89. com y TexasTribune. org. Comunicación y Sociedad, (25), 101-125. https://doi.org/10.32870/cys.v0i25.4423

World Health Organization (2020). Weekly Epidemiological Record, 17 April 2020, vol. 95, 16. Disponible en: http://extranet.who.int/iris/restricted/bitstream/handle/10665/331774/WER9516eng-fre.pdf?ua $=1$ 


\section{AUTORAS}

\section{María Díez-Garrido}

María Díez Garrido es investigadora en Comunicación por la Universidad de Valladolid. Es graduada en Periodismo y cursó el Máster en Investigación como agente histórico-social en la misma universidad. Forma parte del equipo de investigación del proyecto $\mathrm{I}+\mathrm{D}+\mathrm{i}$ "Estrategias, agendas y discursos en las cibercampañas electorales: medios de comunicación y ciudadanos" de la Universidad de Valencia (CSO2016-77331-C2-1-R) y de la Red de Excelencia en Periodismo Digital y Convergencia Mediática (CSO2016-81882-REDT)., financiados por el Ministerio de Economía y Competitividad. Ha colaborado con el Observatorio de Participación Ciudadana, que forma parte de los compromisos del III Plan de Acción de Gobierno Abierto de España, coordinado por el Centro de Estudios Políticos y Constitucionales. Sus trabajos de investigación se centran en la transparencia, el Gobierno abierto y comunicación digital.

maria.diez.garrido@uva.es

\section{Índice H: 4}

Orcid ID: http://orcid.org/0000-0002-5430-7708

Google Scholar: https://scholar.google.es/citations?user=kKOuD_IAAAAJ\&hl=es

ResearchGate: https://www.researchgate.net/profile/Maria_Diez-Garrido

Scopus ID: https://www.researchgate.net/profile/Maria_Diez-Garrido

Academia.edu: https://uva-es.academia.edu/Mar\%C3\%ADaD\%C3\%ADezGarrido

\section{Cristina Renedo Farpón.}

Licenciada en Periodismo por la Universidad de Valladolid (2012) y Máster en Sociedad de la Información y el Conocimiento por la Universitat Oberta de Catalunya (2014). Actualmente es profesora asociada e investigadora predoctoral en la Universidad de Valladolid.

Centra sus líneas de investigación en la apertura mediática, estudiando la participación y transparencia en los medios de Comunicación. Ha participado en diferentes Proyectos I+D vinculados con la comunicación política de la Universidad de Valencia y de la Unviersidad Complutense de Madrid, y forma parte del Grupo de Reflexión y Estudio de la Comunicación Online de la Universidad de Valladolid. En 2017 realizó una estancia de Investigación en el Instituto de la Comunicación de la Universidad de Chile.

cristina.renedo@uva.es

Orcid ID: https://orcid.org/0000-0003-4307-9217

Google Scholar: $\underline{\text { https://scholar.google.es/citations? user= KyxIh4AAAAJ\&hl=es }}$

ResearchGate: https://www.researchgate.net/profile/Cristina_Renedo_Farpon

Academia.edu https://uva-es.academia.edu/CristinaRenedoFarp\%C3\%B3n 


\section{Anexos}

\subsection{Ficha de análisis de la transparencia institucional}

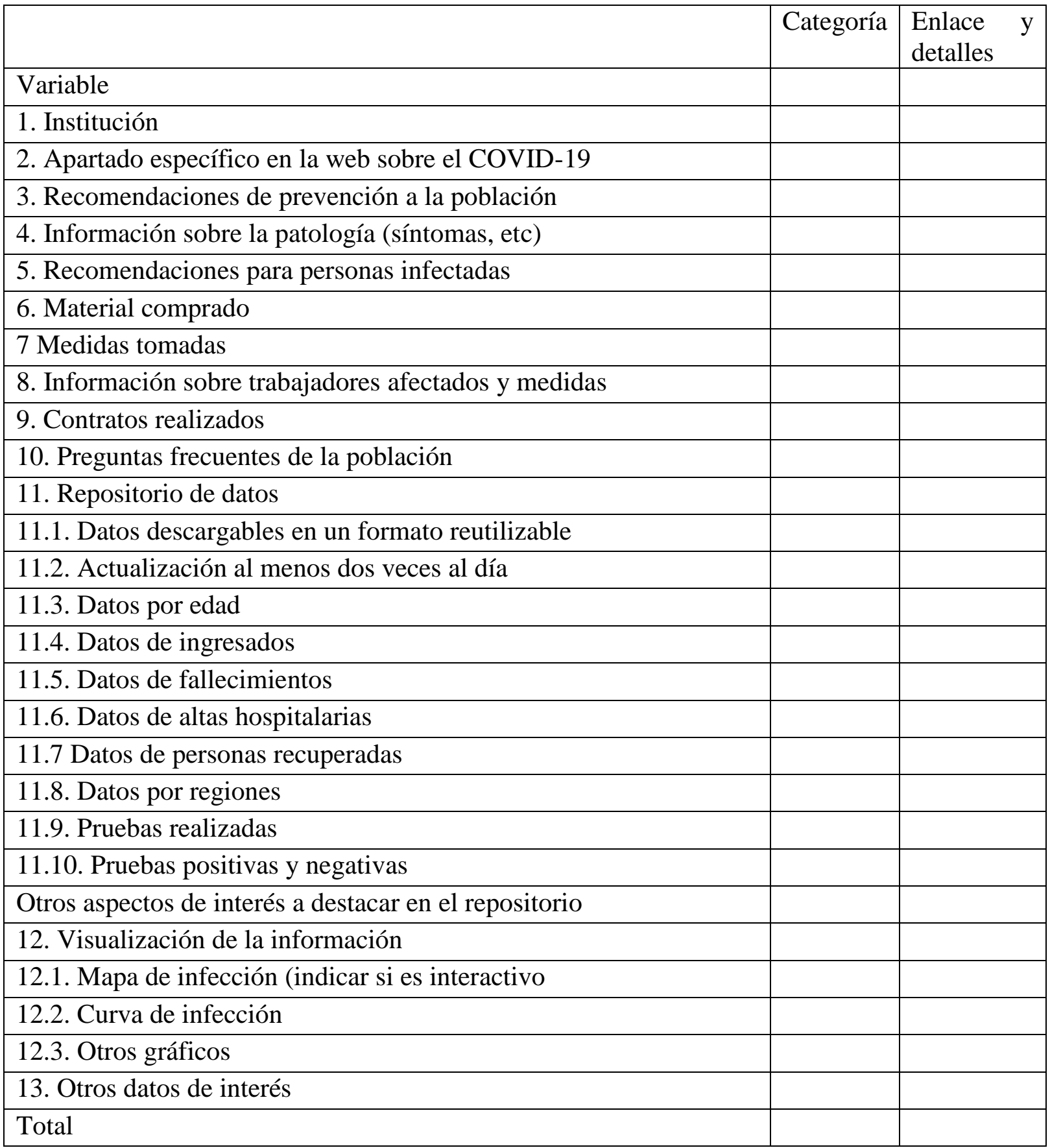

\subsection{Ficha de análisis de los medios de comunicación}

\begin{tabular}{|l|l|l|}
\hline Variable & Categoría & $\begin{array}{l}\text { Enlace y } \\
\text { detalles }\end{array}$ \\
\hline Fecha de codificación & & \\
\hline A) Datos descriptivos & & \\
\hline Medio de comunicación & & \\
\hline Sección especial en la portada sobre coronavirus & & \\
\hline
\end{tabular}


RLCS, Revista Latina de Comunicación Social, 78, 393-418

[Investigación] DOI: 10.4185/RLCS-2020-1482| ISSN 1138-5820| Año 2020

\begin{tabular}{|l|l|l|}
\hline Realiza periodismo de datos & & \\
\hline Mapa interactivo de infección & & \\
\hline Curva de infección & & \\
\hline Otros gráficos & & \\
\hline Realiza fact-checking & & \\
\hline Sección especial de actualización en tiempo real. & & \\
\hline Otras prácticas periodísticas destacadas & & \\
\hline B) Transparencia & & \\
\hline Publican bases de datos & & \\
\hline Publican la metodología utilizada & & \\
\hline Publican las fuentes de forma accesible & & \\
\hline C) Participación y colaboración & & \\
\hline Hay canales de participación específicos del COVID-19 & & \\
\hline Existen vías de colaboración en la elaboración de contenidos & \\
\hline $\begin{array}{l}\text { Existe colaboración con otros medios de comunicación o entidades } \\
\text { (asociaciones, instituciones, etc.) }\end{array}$ & & \\
\hline Otros aspectos destacables & & \\
\hline
\end{tabular}

